\title{
Cord entanglement in monochorionic monoamniotic twins: a case report
}

\author{
Preety Aggarwal $^{1 *}$, Nounenuo Terhase ${ }^{2}$ \\ ${ }^{1}$ Department of Obstetrics and Gynecology, MAMC, Agroha, Hisar, Haryana, India \\ ${ }^{2}$ Primary Health Centre, Mokukchung, Nagaland, India
}

Received: 27 September 2015

Revised: 28 September 2015

Accepted: 30 October 2015

\section{*Correspondence:}

Dr. Preety Aggarwal,

E-mail: ardentpreety@gmail.com

Copyright: $\odot$ the author(s), publisher and licensee Medip Academy. This is an open-access article distributed under the terms of the Creative Commons Attribution Non-Commercial License, which permits unrestricted non-commercial use, distribution, and reproduction in any medium, provided the original work is properly cited.

\section{ABSTRACT}

Monochorionic monoamniotic twin gestations occur in $1 \%$ of all twin pregnancies. They are at increased risk of preterm delivery and acute fetal death. Cord entanglement, malformations, twin to twin transfusion syndrome are responsible for high perinatal mortality and morbidity we report a case of 29 years old primigravida with monoamniotic twins with cord entanglement leading to intrauterine death of both fetuses in MAMC, Agroha.

Keywords: Monochorionic, Monoamniotic, Cord entanglement

\section{INTRODUCTION}

Monochorionic monoamniotic twin gestations occur in about 1 in 8000 pregnancies and, as such, constitute 5\% of monochorionic pregnancies and $1 \%$ of all twin pregnancies. They derived from a single blastocyst in which the zygotic division takes place for more than eightdays after fertilization. They are at increased risk of preterm delivery and acute fetal death. Cord entanglement, malformations, twin to twin transfusion syndrome are responsible for high perinatal mortality and morbidity. Perinatal mortality rate are as high as $28 \%$ to $47 \%$. These high rates are suggested to be specifically due to cord accidents leading to occlusion. Early diagnosis can reduce the complication and most typically diagnosis can be made by early trimester ultrasound showing absence of dividing membrane. The depiction of branching sign of umblical artery by colour Doppler imaging in first trimester sonography was an indication of umblical cord entanglement.

In the present study, we report a case of monoamniotic twins with cord entanglement in MAMC, Agroha.

\section{CASE REPORT}

A 29yr old unbooked, Mrs. N, a primi gravida, from agroha attended emergency Obstetrics and Gynaecology OPD, MAMC on 02-07-2015 at 12.16 pm with A 31 weeks of pregnancy with complaints of pain abdomen and decreased fetal movements for last 2 days.

On examination, patient was afebrile. Pulse rate was 90/min and B.P-120/88 mm Hg. Abdominal examination revealed uterus corresponding to 32 wks size. The FHS was not localised. On vaginal examination, cervix was 2 $\mathrm{cm}$ dilated. Routine haematological investigations showed haemoglobin $10.2 \mathrm{gm} \%$, Total Leucocyte count $10,400 /$ cumm, Differential count (polymorphs $70 \%$, lymphocyte $26 \%$, monocyte $3 \%$ and eosinophil $1 \%$ ), ESR $5 \mathrm{~mm} / 1 \mathrm{st}$ hour, Platelet count $2.1 \mathrm{lacs} / \mathrm{cumm}$. Kidney function test showed blood urea $16 \mathrm{mg} \%$ and serum creatinine $0.6 \%$. Urinalysis, serum electrolytes, Liver function test, blood sugar were within normal limits.

TAS USG was done, which showed that its twin IUD of 30 weeks gestation. Patient was already in latent labor, 
which was augmented with oxytocin drip of $2 \mathrm{Miu} / \mathrm{min}$, she delivered both the dead fetus by cephalic presentation at $2.03 \mathrm{pm}$, placenta with both the cords were expelled immediately, with cords showing multiple true knots with entanglements. Patient did not develop any complication intrapartum or postpartum and was discharged after one day of hospital stay.

\section{DISCUSSION}

Monochorionic monoamniotic twin gestations derived from a single blastocyst in which the zygotic division takes place for more than eight days after fertilization. Monoamniotic twins are rare. They occur in about 1 in 8000 pregnancies and, as such, constitute 5\% of monochorionic pregnancies. These twins share a placenta as well as an amniotic sac. As both are in the same sac, cord entanglement is expected. Cord entanglement is the main risk of these pregnancies. They develop in very early gestational ages and become a crucial problem in later weeks.

In multiple gestations, widespread application of first trimester transvaginal sonography has enabled precise depiction of chorionicity and amniocity. Sherer et al stated in a case report that the depiction of branching sign of umblical artery by colour Doppler imaging in first trimester sonography was an indication of umblical cord entanglement. Doppler flow velocimetry may reflect hemodyanamic alterations in the fetoplacental circulation secondary to narrowing of the umblical vessels involved in cord entanglement, such as a 'notch' in umblical artery waveform.

Eserdag et al studied that perinatal mortality in monochorionic monoamniotic twin gestations is as high as $28 \%$ to $47 \%$. Umbilical cord entanglements and knots, twin-to-twin transfusion syndrome, congenital anomalies, prematurity and intertwin locking during labor is responsible for their high perinatal morbidity and mortality. ${ }^{1}$

In contrast to this, recent studies by Rossi shows that Cord entanglement does not contribute to prenatal morbidity and mortality in monoamniotic twin pregnancies. $^{2}$

So, as there is associated high morbidity and mortality with this condition, early and accurate prenatal diagnosis and management is associated with improved perinatal survival. This is studied by Ezra Y et al which shows that early diagnosis, close in-hospital antenatal surveillance starting at fetal viability, and elective delivery at 32 weeks would reduce the antenatal mortality. This early elective delivery to reduce the complication in monochorionic monoamniotic twins are opposed by Dias
$\mathrm{T}$ and his colleagues in their study which stated that perinatal mortality in monoamniotic twins is mainly aconsequence of conjoined twins, TRAP, discordant

anomaly and spontaneous miscarriage before 20 weeks' gestation. Expectantly managed monoamniotic twins after 20 weeks have a very good prognosis despite the finding of cord entanglement. The practice of elective very preterm delivery or other interventions to prevent cord accidents in monoamniotic twins should be reevaluated. ${ }^{3}$

Finally, regarding mode of delivery, most units would offer a Cesarean birth to avoid cord prolapse or inadvertent clamping of the cord of the second twin, which may be wrapped tightly around the neck of the first. But still there is still no consensus in literature for the management and the mode of delivery of these rarely encountered cases. ${ }^{4}$

\section{CONCLUSIONS}

In summary, monoamniotic monochorionic twin pregnancies have an increased risk of cord entanglement, twin- to- twin tansfusion syndrome, prematurity and congenital malformations. Early and accurate antenatal diagnosis is the mainstay in the management of such cases. In order to define the optimal route of delivery in these pregnancies, we need controlled and prospective studies.

\section{Funding: No funding sources \\ Conflict of interest: None declared \\ Ethical approval: Not Required}

\section{REFERENCES}

1. Eserdag S, Zulfikaroglu E, Ozer A. Cord entanglement in monochorionic monoamniotic twins. Bratisl Lek Listy. 2010;111(12):673-5.

2. Rossi AC, Prefumo F. Impact of cord entanglement on perinatal outcome of monoamniotic twins: a systematic review of the literature. Ultrasound Obstet Gynecol. 2013;41(2):131-5.

3. Dias T, Mahsud-Dornan S, Bhide A, Papageorghiou AT, Thilaganathan B. Cord entanglement and perinatal outcome in monoamniotic twin pregnancies. Ultrasound Obstet Gynecol. 2010;35:201-4.

4. Eserdag S, Zulfikaroglu E, Ozer A. Cord entanglement in monochorionic monoamniotic twins. Bratisl Lek Listy. 2010;111(12):673-5.

Cite this article as: Aggarwal $\mathrm{P}$, Terhase N. Cord entanglement in monochorionic monoamniotic twins: a case report: a rare case report. Int J Reprod Contracept Obstet Gynecol 2015;4:2091-2. 